\title{
Dental considerations and management in Noonan Syndrome: A case report with review of literature
}

(D) Nipun Jain ${ }^{1}$, (D) Priyanka Venugopal ${ }^{2}$, (D) Arun Mamachan Xavier ${ }^{3}$, (D) Parvathy Kumaran ${ }^{4}$, (D) Balagopal R Varma ${ }^{5}$, (D) Suresh Kumar $\mathrm{J}^{6}$

\section{Highlights}

Noonan syndrome is a relatively common genetic disorder seen in dental practise.
Not all dental characteristic features are seen at a given time.
Children with Noonan syndrome are generally uncooperative in dental chair and owing to their systemic complications; dental management is mostly carried out under general anaesthesia.
1 Post Graduate Student, Department of Pediatric and Preventive Dentistry, Amrita School of Dentistry, Amrita Vishwa Vidyapeetham, Kochi, Kerala, India

2 Post Graduate Student, Department of Pediatric and Preventive Dentistry, Amrita School of Dentistry, Amrita Vishwa Vidyapeetham, Kochi, Kerala, India

${ }^{3}$ Reader, Department of Pediatric and Preventive Dentistry, Amrita School of Dentistry, Amrita Vishwa Vidyapeetham, Kochi, Kerala, India

4 Professor, Department of Pediatric and Preventive Dentistry, Amrita School of Dentistry, Amrita Vishwa Vidyapeetham, Kochi, Kerala, India

5 Professor, Department of Pediatric and Preventive Dentistry, Amrita School of Dentistry, Amrita Vishwa Vidyapeetham, Kochi, Kerala, India

${ }^{6}$ Professor, Department of Pediatric and Preventive Dentistry, Amrita School of Dentistry, Amrita Vishwa Vidyapeetham, Kochi, Kerala, India

\section{Correspondence:}

Department of Pediatric and Preventive Dentistry, Amrita School of Dentistry, Amrita Vishwa Vidhyapeetham, Kochi, India E-mail address: arunmamachan@yahoo.co.in

\section{Abstract}

Noonan syndrome is a genetic disorder of autosomal dominance with an estimated prevalence of 1:1000 - 1:2500 live birth. The typical features include short stature, cardiovascular abnormalities and characteristics facial deformity. Dental features reported so far include malocclusion, dental caries, giant cell and cystic lesion. Multidisciplinary treatment plays a key role in the overall quality of life of the patient. This case report describes a 6-year-old boy with Noonan syndrome who required comprehensive dental treatment under general anaesthesia.

Keywords: Cardiovascular Abnormalities; Comprehensive Dental Care; Noonan Syndrome

Received: 13 May 2021

Accepted: 15 June 2021

Online First: 23 June 2021 


\section{INTRODUCTION}

In 1963, Noonan and Ehmke ${ }^{1}$ described Noonan syndrome as a relatively common genetic multisystem disorder, resembling Turner syndrome, but without chromosomal anomaly and high portion of maternal transmission. Affected individuals have peculiar facial features, short stature with congenital cardiac abnormality and chest deformity. Diagnostic criteria is based on the facial, musculoskeletal feature with genetic mutations in the SOS1, MEK1, LZTR1, BRAF, KRAS, RRAS, RASA2, NRAS, RIT1, A2ML1, RAF1, MAP2K1, SOS2, ADNP, p.Gly503Arg and p.Met504Val with RIT1 being one of the major genes. ${ }^{2}$

Characteristic facial features seen during infancy become indistinct towards the later stages of life. Features range from small face with a large head, hypertelorism, low-set ears, short nose to wide forehead, prominent chin, webbed neck, rounded shoulders and hyperextensibility of joints. ${ }^{3}$ Other characteristics including vision and hearing defects, malignant hyperthermia, bleeding tendencies, digestive disorders, delayed puberty, delayed motor development and speech have also been reported. ${ }^{4}$ The clinical features and pathogenesis of Noonan syndrome is related to certain syndromes like, Noonan syndrome with multiple lentigines or LEOPARD syndrome, Neurofibromatosis type 1 , cardiofaciocutaneous syndrome and Costello syndrome. ${ }^{5}$

Wide range of intra oral features ranging from high arched palate, multiple dental caries to multiple odontogenic keratocyst and giant cell lesions have been reported in the literature.6,7 Dental management in these children should be carried out with great caution owing to their systemic complications. This case report emphasises on the dental considerations and management of a male child with Noonan syndrome who required comprehensive dental rehabilitation under general anaesthesia.

\section{CASE REPORT}

A six-year-old male patient was referred to the Department to eradicate the dental foci of infection by a Pediatric Cardiologist of a tertiary health care center. Natal history revealed full-term delivery by $\mathrm{C}$-section, and second birth order to a non-consanguineous couple. The patient's medical history revealed Noonan syndrome with sub-valvular and valvular pulmonary valve stenosis and had undergone balloon pulmonary valvuloplasty. He had also undergone left laproscopic Orchidopexy and Right Fowler Stephen stage I and II, in 2019. Patient had to be planned for elective ICR after Dental rehabilitation.

Patient was examined extraorally and intraorally. On general examination, the child was conscious, co-operative, with no signs of pallor, icterus, cyanosis, clubbing and lymphadenopathy. There were no relevant prenatal and natal developmental histories. Postnatally child was breastfed for 2 years. Delay in the post-natal milestones of development pertaining to motor coordination and speech were evident.

Growth charts were prepared to record the growth percentiles. Value of height recorded was below the $3^{\text {rd }}$ percentile, suggestive of generalised retarded growth pattern (Table 1) (Figure 1). On clinical examination, the patient presented with a short statue. Extraoral features revealed a normal facial profile with prominent lower lips, mid face deficiency, deeply grooved philtrum, hypertelorism, ptosis, low set ears, flat base of nose, webbed neck, low posterior hair line, and with competent lips (Figure 2). 
Table 1. Growth percentiles in each group (height, weight and BMI) according to World Health Organisation child growth standards ${ }^{8}$

\begin{tabular}{llllll}
\hline SI.no & Parameters & Obtained value & Growth percentile & $\begin{array}{l}\text { Value at } \mathbf{5 0}^{\text {th }} \\
\text { percentile }\end{array}$ & Expected age \\
\hline 1. & Height & $106.5 \mathrm{cms}$ & $<3^{\text {rd }}$ percentile & $117.9 \mathrm{cms}$ & $4-5$ years \\
\hline $\mathbf{2 .}$ & Weight & $17 \mathrm{~kg}$ & $<5^{\text {th }}$ percentile & $21.3 \mathrm{~kg}$ & $4-5$ years \\
\hline 3. & BMI & $15 \mathrm{~kg} / \mathrm{m}^{2}$ & $<50^{\text {th }}$ percentile & $15.4 \mathrm{~kg} / \mathrm{m}^{2}$ & $4-5$ years \\
\hline
\end{tabular}

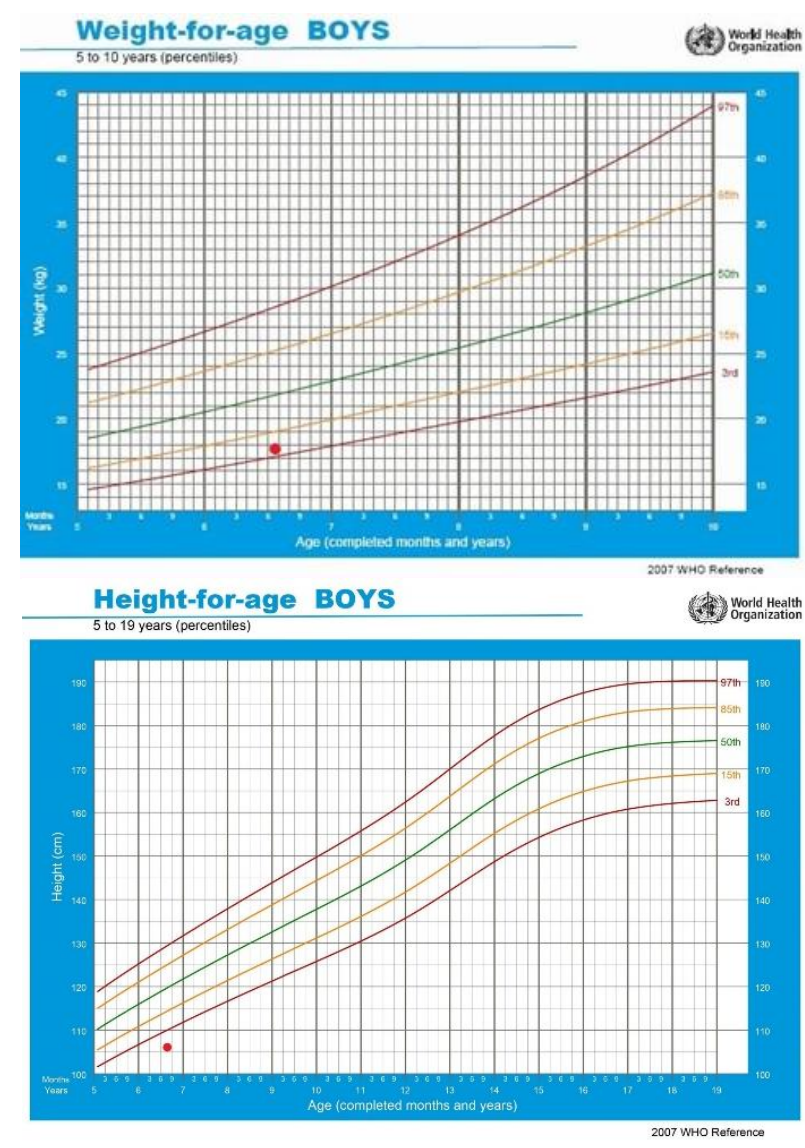

On intraoral examination, mixed dentition with poor oral hygiene and multiple carious teeth were evident with a history of restoration done from a private clinic in relation to a mandibular posterior tooth. The child's mother reported to have brushed his teeth once daily with no other hygiene aids used. With respect to soft tissue examination, there were no abnormalities of mucosa, floor of mouth and tongue. Clinically, the U-shaped maxillary arch revealed a depression in the mid palatal area with no history of cleft palate repair, suggestive of developmental deformity in the fusion of the palatal shelves. Mandibular arch was U-shaped with class III malocclusion and cross bite in relation to 53 and 63. Generalized deep carious lesions and root stumps were noticed (Figure 3A, B). An Orthopantomogram revealed normal dental age and development. Condyles appeared to be normal, with no signs of ankylosis (Figure 3C).

Figure 1. WHO Growth chart depicting age wise height and weight percentiles. ${ }^{8}$
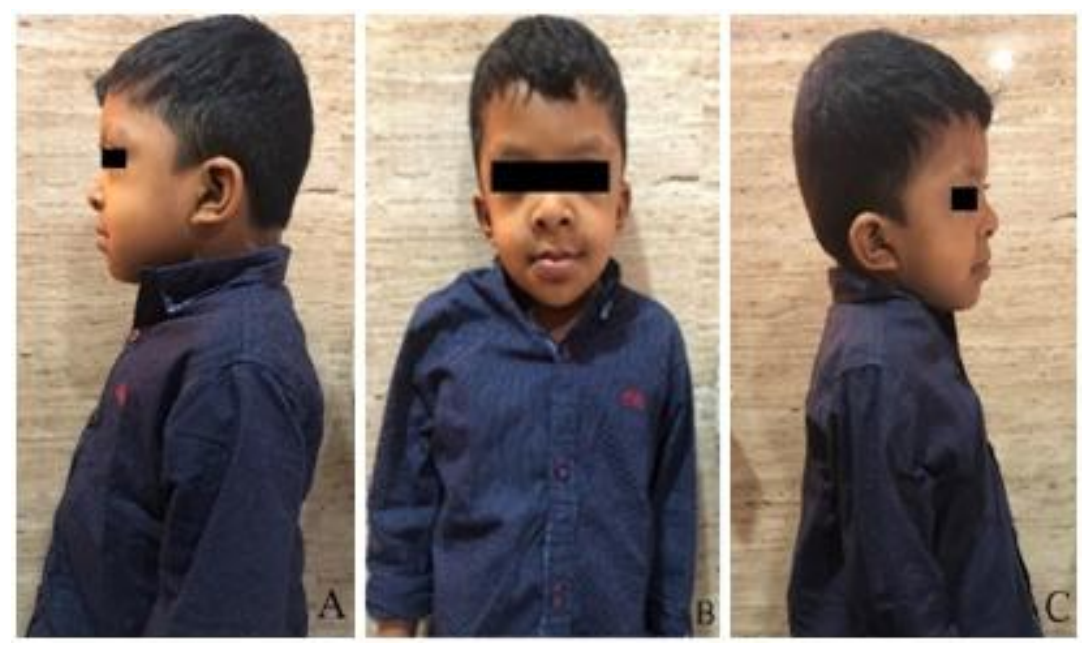

Figure 2. Profile image. A: Left lateral view; B: Frontal view; C: Right lateral view 

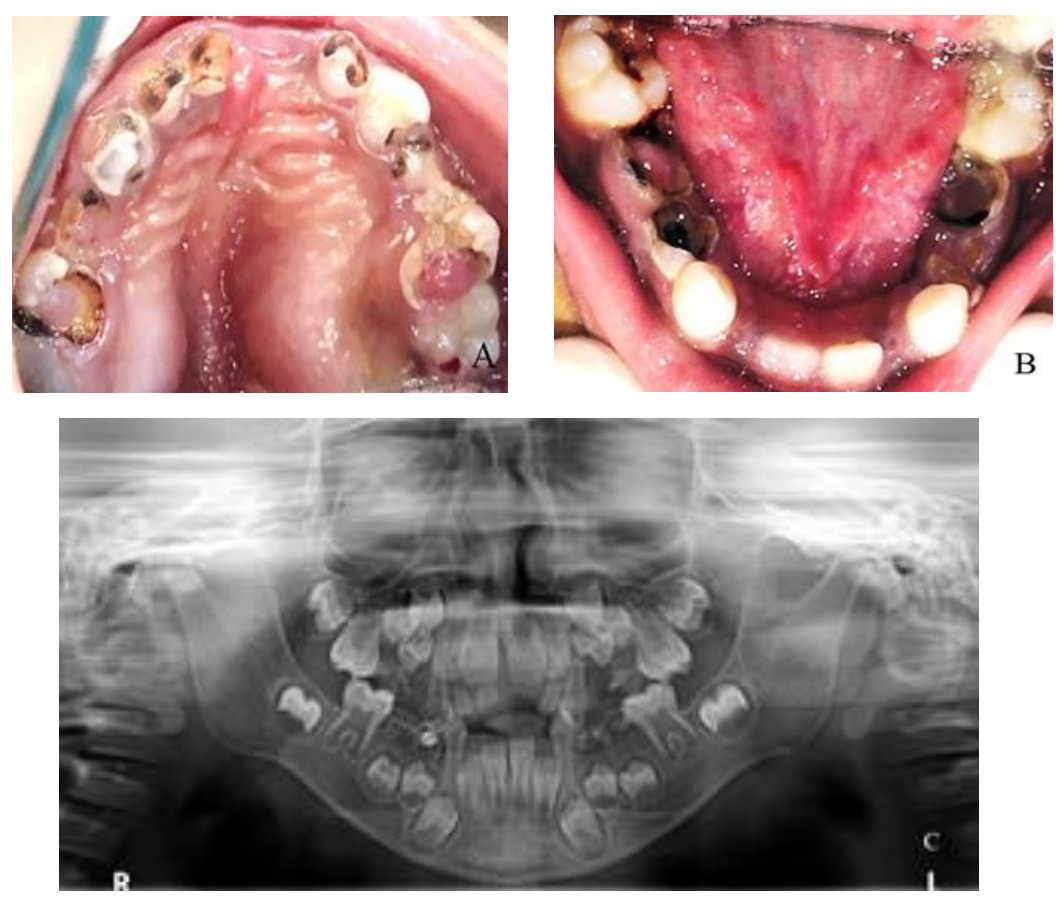

Figure 3. Pre opeartive photographs. A: Maxillary occlusal view; B: Mandibular occlusal view; C: Orthopantomogram

Decision to perform comprehensive dental rehabilitation under general anesthesia was planned and informed consent was obtained for the same from the parents. Procedure was carried out under antibiotic prophylaxis (Inj. Ceftriaxone $50 \mathrm{mg} / \mathrm{kg} / \mathrm{wt}, 30$ minutes prior surgery). The dental treatment consisted of extraction of all the deciduous maxillary molars, cental and lateral incisors, and mandibular deciduous molars. Resorbable 3-0 vicryl sutures were placed in the extraction sockets to attain hemostasis. Pulpectomy with zinc oxide eugenol was done in the deciduous maxillary canines and restored with Type IX Glass ionomer cements. Indirect pulp capping with Dycal and Type IX glass ionomer cement was done with respet to right lower permanent first molar (Figure 4A, B). Recovery was uneventful.

\section{DISCUSSION}

Noonan syndrome is a genetic disorder of autosomal dominance with prevalence of 1:1000 1:2500 live births. ${ }^{1}$ This condition can often go undiagnosed into the adulthood until these patients exhibit characteristic features and associated systemic manifestations.

Patients with Noonan Syndrome have a normal karyotype with common genetic mutation of PTPN 11 gene. The mutation of this gene alters RAS-mitogen activated protein kinase (MAPK) pathway, thereby affecting extracellular ligands like growth factors, cytokines, and hormones on their cellular functions. ${ }^{?}$

Van der Burg et al. ${ }^{10}$ developed a scoring system where presence of one major/ two minor and two major/ one minor sign is required for the diagnosis of Noonan syndrome (Table 2).

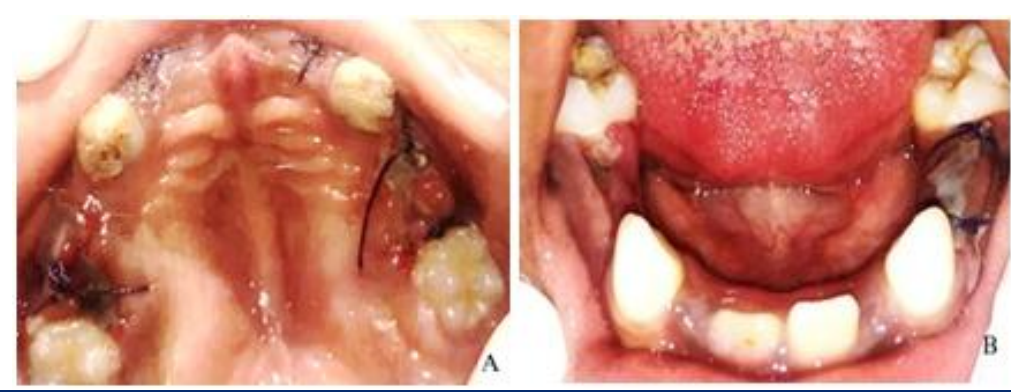

Figure 4. Post operative photographs. A: Maxillary occlusal view; B: Mandibular occlusal view 
Table 2. Diagnostic criteria for Noonan syndrome

\begin{tabular}{lll}
\hline Features & Major & Minor \\
\hline Face & Facial features - Typical & Facial features - Suggestive \\
\hline Cardiac & Pulmonary valve stenosis & Other defects \\
\hline Chest wall & Pectus carniatum/ excavatum & Broad thorax \\
\hline Height & $<3^{\text {rd }}$ percentile & $<10^{\text {th }}$ percentile \\
\hline Family history & Definite Noonan syndrome in first dregree & $\begin{array}{l}\text { Suggestive Noonan syndrome in first dregree } \\
\text { relative }\end{array}$ \\
& relative
\end{tabular}

In the present case, patients birth record revelaved normal height and weight, but his growth pattern had decreased to the $3^{\text {rd }}$ percentile over years which in consistent with the findings of Athota et al. ${ }^{11}$ and Kouz et al. ${ }^{12}$ The distinguishing features evident in this case include, short stature, chest deformity, congenital cardiac abnormalities, hypertelorism, ptosis, facial deformity, low set ears, deep grooved philtrum and low posterior hair line. Thus, satisfying two major/ one minor sign of Van der Burg's diagnostic criteria. In general, the growth pattern of these patients is attenuated during puberty and their final adult height is also below the normal range. ${ }^{9}$ Literature shows a general developmental delay in the mean age of motor milestones, including cognitive issues and learning disabilities. ${ }^{1,13}$ Same with the current case, patient was able to stand without support and walk only by age three, while ability to speak and respond to questions was attained only around five years of age. Most affected children have normal intelligence; however their IQ when compared to unaffected family members have been shown to be 10 points lesser. ${ }^{13}$

Differential diagnosis of Noonan syndrome includes Turner syndrome that has cardiac features typically left-sided compared to rightsided in Noonan's syndrome. Other disorders with significant phenotypic overlap with Noonan syndrome are enlisted in (Table 3). 5,14

Table 3. Differential diagnosis of Noonan syndrome

\begin{tabular}{llll}
\hline Syndrome & Associated genes & Craniofacial findings & Dental findings \\
\hline Neurofibromatosis type I & NF1 & $\begin{array}{l}\text { Multiple café au lait, cutaneous } \\
\text { neurofibroma, iris Lisch nodules }\end{array}$ & $\begin{array}{l}\text { Hypolplastic mandible, } \\
\text { retained deciduous teeth, } \\
\text { mandibular cysts }\end{array}$ \\
& & & \\
\hline $\begin{array}{l}\text { NS with multiple } \\
\text { lentigines }\end{array}$ & RAF1, PTPN11, & $\begin{array}{l}\text { NS- like facies, heart defects with } \\
\text { recurrance at different frequencies, } \\
\text { multiple lentigines, occular } \\
\text { hypertelorism }\end{array}$ & $\begin{array}{l}\text { Missing primary and } \\
\text { permanent teeth, High arch } \\
\text { palate }\end{array}$ \\
& & $\begin{array}{l}\text { Severe feeding difficulty, } \\
\text { absent/sparse eyebrows and } \\
\text { eyelashes, hyperkeratotic skin and } \\
\text { facial dysmorphism, depressed } \\
\text { nasal bridge }\end{array}$ & Posterior cross bite, and open \\
(CFC) syndrome & KRAS, MAP2Kite High arched palate & \\
& BRAF, MAP2K2 & \\
& &
\end{tabular}


Intra-oral manifestation are not as conspicous as other features asociated with Noonan syndrome. Baird and De Jong ${ }^{15}$ in 1972, were the first to report the oral manifestations in a family over a period of three generations. Over the subsequent years, authors have mentioned various intra-oral features including malocclusion, ${ }^{16-23}$ high arch palate, ${ }^{19,23-25}$ multipe decayed teeth, ${ }^{16}$ anterior open bite, ${ }^{16,23,25,26}$ prognatic mandible, ${ }^{18,23,26}$ retrognathic maxilla, ${ }^{18,26}$ deep bite, ${ }^{20,21}$ cross bite, ${ }^{10,19,25}$ traudontism, ${ }^{19}$ ectopically positioned teeth, ${ }^{21}$ hypodontia, ${ }^{19-21}$ enamel hypolasia, ${ }^{3}$ dilacerations, articulation difficulties, dental erosion, gingival inflammation, ${ }^{17-19}$ multiple odontogenic keratocyst ${ }^{14,27}$ and giant cell lesions. ${ }^{21,27}$ Consistent with the literature this patient presented with malocclusion, high arch palate, multipe decayed teeth, retrognathic maxilla, prognathic mandible, anterior crossbite. These manifestations can lead to feeding difficulties resulting in the retardation of growth, calling for immediate multidisciplinary management.

Patients with Noonan syndrome often manifest congential cardiac abnormalities. Pulmonary valve stenosis is the most common condition encountered, which often requires periodic re-evaluation. Dental treatment should thus be proceeded with caution in preventing infective endocardititis. Prior to procedure prophylactic antibotics and consent from a pediatric Cardiologist may be required.

Treatment under general anesthesia is of major concern in these patient owing to their systemic complications. Presence of high arched palate, short webbed neck, micrognathia, and malocclusion make intubation difficult in these patients. Difficult airway equipment should be readily available, and fiberoptic intubation may be necessary. ${ }^{29}$ Patients should be adequately hydrated prior to anaesthetic induction so as to avoid hypotension from the sympathetic blockage, which could lead to decrease in right ventricular output and cardiac arrest. Increasing intravascular volume should only be done with caution as it could precipitate right ventricular failure. ${ }^{30}$ Ventilation must be carefully monitored and managed so as to avoid hypercarbia, hypoxia and high peak airway pressures that may exacerbate pulmonary hypertension. ${ }^{31}$

About $30 \%$ to $65 \%$ of individuals with Noonan syndrome exhibit disordered bleeding. Although the symptoms are often mild, excessive bleeding may be anticipated in major surgeries. ${ }^{13}$ In current case, the patient did not experience a bleeding disorder and post-operative haemostasis was satisfactory. Atraumatic extractions should be considered to avoid excessive bleeding; however, in cases of extraction, haemostasis must be achieved either with sutures or other aids.

\section{CONCLUSIONS}

Individuals with Noonan syndrome often exhibit a wide range of health problems. Prognosis solely depends on the severity of clinical features and the associated systemic conditions. Knowledge on the specific characteristics of Noonan syndrome among dental practitioners enables them to provide parents with adequate counselling and optimal management. Awareness and education among parents must be ensured, emphasizing the importance of first dental visit once the first tooth erupts.

\section{REFERENCES}

1. Noonan JA. Noonan Syndrome: An Update and Review for the Primary Pediatrician. Clin Pediatr (Phila) 1994;33:548-555

2. Alhassoun R. Clinical manifestation and dental management of Noonan Syndrome. Int Med 2020;2:260

3. Mallineni SK, Yiu CKY, King NM. Oral manifestations of Noonan syndrome: Review of the literature and a report of four cases. Rom J Morphol Embryol 2014;55:1503-1509 
4. Lutz JC, Nicot R, Schlund M, Schaefer E, Bornert F, Fioretti F, et al. Dental and maxillofacial features of Noonan Syndrome: Case series of ten patients. J Cranio-Maxillofacial Surg 2020;48:242-250

5. Tartaglia M, Gel ZM. Noonan syndrome and clinically related disorders. Best Pract Res Clin Endocrinol Metab 2011;25:161-179

6. Hwang I, Lee Y, Sim D, Mah Y. Oral Features in a Child with Noonan Syndrome: A Case Report. J Korean Acad Pedtatric Dent 2018;45:115-122

7. Anthonappa RP, King NM. Oral and dental manifestations in noonan syndrome. In: Amrit Bhangoo, editors. Noonan Syndrome: Characteristics and Interventions. Academic Press; 2019. p.135-158

8. WHO Child Growth Standards. Dev Med Child Neurol 2009;51:1002-1002

9. Malaquias, A. C., \& Jorge, AAL. Growth Failure and Experience With Growth Hormone Therapy in Noonan Syndrome. In: Amrit Bhangoo, editor. Noonan Syndrome: Characteristics and Interventions. Academic Press; 2019. p.15-29

10. Van der Burgt I, Berends E, Lommen E, Van Beersum S, Hamel B, Mariman E. Clinical and molecular studies in a large Dutch family with Noonan syndrome. Am J Med Genet 1994;53:187-191

11. Athota, JP, Bhat, M, Nampoothiri, S, Gowrishankar K, Narayanachar SG, Puttamallesh $\mathrm{V}$, et al. Molecular and clinical studies in 107 Noonan syndrome affected individuals with PTPN11 mutations. BMC Med Genet 2020;21:50

12. Kouz K, Lissewski C, Spranger S, Mitter D, Riess A, Lopez-Gonzalez V et al. Genotype and phenotype in patients with Noonan syndrome and a RIT1 mutation. Genet Med 2016;18:12261234

13. Romano AA, Allanson JE, Dahlgren J, Gelb BD, Hall B, Pierpont ME, et al. Noonan syndrome: Clinical features, diagnosis, and management guidelines. Pediatrics 2010;126:74659

14. Cao H, Alrejaye N, Klein OD, Goodwin AF, Oberoi S. A review of craniofacial and dental findings of the RASopathies. Orthod Craniofacial Res 2017;20:32-8
15. Baird PA, De Jong BP. Noonan's syndrome (XX and XY Turner phenotype) in three generations of a family. J Pediatr 1972;80:110-114 16. Barberia Leache E, Saavedra Ontiveros D, Maroto Edo M. Etiopathogenic analysis of the caries on three patients with Noonan Syndrome. Med Oral 2003;8:136-142

17. Sharma PR, MacFadyen UM, Fung DE. Dental management of a child patient with Noonan's syndrome. Dent Update 2007;34(2):117-118, 120

18. Ortega Ade O, Guaré Rde O, Kawaji NS, Ciamponi AL. Orofacial aspects in Noonan syndrome: 2 case report. J Dent Child (Chic) 2008; 75:85-90

19. Sahebjamee M, Ameri NG, Farhud DD. First report of new oral findings in a case with Noonan syndrome. Iranian J Publ Health 2008;37:131-137

20. Emral ME, Akcam MO. Noonan syndrome: a case report. J Oral Sci 2009;51:301-306.

21. Ierardo G, Luzzi V, Panetta F, Sfasciotti GL, Polimeni A. Noonan syndrome: a case report. Eur J Paediatr Dent 2010;11:97-100

22. Bufalino A, Carrera M, Carlos R, Coletta RD. Giant cell lesions in Noonan syndrome: case report and review of the literature. Head Neck Pathol 2010;4:174-177

23. Sugar AW, Ezsias A, Bloom AL, Morcos WE. Orthognathic surgery in a patient with Noonan's syndrome. J Oral Maxillofac Surg 1994;52:421425

24. Nirmal T, Muthu MS, Arranganal P. Noonan syndrome: a case report. J Indian Soc Pedod Prev Dent 2001;19:77-79

25. Okada M, Sasaki N, Kaihara Y, Okada R, Amano H, Miura K, Kozai K. Oral findings in Noonan syndrome: report of a case. J Oral Sci 2003;45:117-121

26. Asokan S, Muthu MS, Rathna Prabhu V. Noonan syndrome: a case report. J Indian Soc Pedod Prev Dent 2007;25:144-147

27. Morice A, Harroche A, Cairet P, Khonsari RH: Preoperative detailed coagulation test are required in patients with Noonan syndrome. J Oral Maxillofac Surg 2017;76: 1553-1558.

28. Cancino CMH, Gaião L, Sant'Ana Filho M, Oliveira FAM, Giant cell lesions with a Noonan like phenotype: a case report, J Contemp Dent Pract, 2007, 8(4):67-73. 
29. Aggarwal V, Malik V, Kapoor PM, Kiran U. Noonan syndrome: An anesthesiologist's perspective. Ann Card Anaesth 2011;14:214-217

30. Shah, S. Analgesia, Anesthesia, and Perioperative Considerations in Noonan Syndrome. Noonan Syndrome. In: Amrit Bhangoo, editors. Noonan Syndrome: Characteristics and Interventions. Academic Press; 2019. p.123-134

31. Bajwa SJS, Gupta S, Kaur J, Panda A, Bajwa SK, Singh A, et al. Anesthetic considerations and difficult airway management in a case of Noonan syndrome. Saudi J Anaesth 2011;5:345-347

\section{How to cite this article:}

Nipun Jain, Priyanka Venugopal, Arun Mamachan Xavier, Parvathy Kumaran, Balagopal R Varma, Suresh Kumar J. Dental considerations and management in Noonan Syndrome: A case report with review of literature. Contemp Pediatr Dent 2021:2(2):55-62. DOI: $10.51463 /$ cpd.2021.57

\section{Declarations}

Acknowledgements: Not applicable.

Conflict of Interest Statement: Authors disclose no potential conflicts of interest.

Ethics Statement: Procedure was explained to the legal guardian and written consent was obtained for the treatment and publication of the case report.

Informed Consent: Informed consent was taken from legal guardian.

Author contributions: Conception and design: All Authors; Acquisition of data: NJ, PV, AMX; Interpretation of data: NJ, PV, AMX; Drafting article: NJ, PV, AMX; Revision artice: $A$ NJ, PV, AMX, PK; Final approval: All Authors

Funding: This work is not finantiated.

Data Availability: The data used to support the findings of this study can be made available upon request to the corresponding author.

Peer-review: Externally double-blinded peer-reviewed. 